\title{
ФАКТОРЫ ТЕХНОЛОГИЧЕСКОГО РАЗВИТИЯ ПРЕДПРИЯТИЙ ОТЕЧЕСТВЕННОГО МАШИНОСТРОЕНИЯ
}

\author{
(c) 2018 Якунин Алексей Витальевич \\ Самарский государственный экономический университет \\ 443090, г. Самара, ул. Советской Армии, 141
}

Рассмотрены вопросы оценки основных факторов, влияющих на темпы развития ведущих технологий в отечественном машиностроении. Обозначены резервы повышения эффективности использования научно-технологического потенциала предприятий российского машиностроения на основе совершенствования организационно-экономических механизмов в системе производственной деятельности.

Ключевые слова: факторы, инновации, технологии, машиностроение, потенциал, развитие, резерBbl.

Современные исследования состояния отечественного машиностроения показывают, что наиболее слабым звеном в системе развития производственного потенциала в настоящих условиях становится технология, роль которой закономерно возрастает.

Анализ темпов развития машиностроения России и зарубежных стран подтверждает, что общее отставание темпов развития нашего машиностроения зависит, в первую очередь, от темпов развития технологий. Низкие темпы развития технологического потенциала «формируют» и низкие технико-экономические показатели на большинстве предприятий машиностроительного комплекса. в машиностроении России характерными признаками являются: преимущественно экстенсивное развитие; низкие темпы эффективности труда работающих; медленный рост коэффициента использования металла; низкий уровень энергоотдачи. При этом отмечается недостаток инвестиций на проведение научных исследований. За последние годы в машиностроительном комплексе страны не выполнены многие государственные научно-технические программы, которые должны были при их реализации обеспечить значительный прирост научно-технологического потенциала промышленных предприятий. в машиностроении за последние 20 лет существенно не изменилась динамика структуры особенно технологических процессов в обрабатывающих производствах. В условиях НТП прогрессивные энергоносители в машиностроении оказывают значительное влияние на осуществление инженерно-технических мероприятий, направленных на обеспечение экономически оптимальной длительности жиз- ненного цикла оборудования. При этом появляются сложные научно-методические проблемы накопления информации об экономичности отдельных этапов функционирования оборудования в конкретных производственно-хозяйственных условиях. Сложной является проблема функционального и технологического «сопряжения» машиностроения и предприятий металлургии (черной и цветной). Сложная проблема «встраивания» машиностроения в систему базовых отраслей промышленности, имеющих общегосударственные приоритеты в связи с реализацией задач повышения технологического потенциала, технологической независимости и экономической безопасности. С 1993-1995 гг. остаются вопросы управления в машиностроении в системе базовых отраслей экономики России. Определяется это особой структурно-технологической взаимозависимостью подотраслей отечественного машиностроения, сложностью производимой продукции и особенностями межотраслевой специализации и кооперирования. Следует отметить, что разрушение единого технологического, информационного и экономического пространства в 1994-2012 гг. привело к падению общего производственного потенциала отечественного машиностроения. Наиболее сложная проблема - недостаток качественной рабочей силы (в том числе и на предприятиях ОПК, входящих в состав предприятий машиностроения).

В отечественном машиностроении, который определяет темпы развития ведущих отраслей материального производства, в 2008-2014 гг. замедлились темпы НИОКР, уровень конкурентоспособности наукоемкой продукции практи- 
чески не повышается: недостаточно качество рабочей силы; низки темпы развития новых технологий. За этот период снизились темпы электровооруженности и технической оснащенности производства, что затрудняет решение вопросов перехода к производству новой продукции. все это приводит к снижению технико-организационного уровня производства предприятий машиностроения и его экономической результативности.

Очень часто проводимая реструктуризация машиностроительных предприятий не решает организационно-экономических вопросов совершенствования материально-технической базы. Например, в ряде подотраслей машиностроения сокращение объемов НИОКР привело к снижению уровня технологической оснащенности производства, что предопределило снижение степени готовности к выпуску новой продукции. В машиностроении на многих предприятиях ОПК нет необходимой государственной поддержки научно-технологического развития. Пока в машиностроении нет механизмов такой поддержки, как нормативно-правовая база, кадровое, информационное и научное обеспечение; инвестиционное и инфраструктурное обеспечение. В машиностроении растет негативное влияние факторов энерготехнологической многоукладности. Сложная ситуация складывается в заготовительных производствах предприятий машиностроения, где темпы технологического развития остаются низкими. во многих подотраслях машиностроения нет программ поддержки сохранения отраслевых НИИ и материально-технической базы опытно-экспериментальных производств предприятий, имеющих высокую долю производства сложной наукоемкой продукции; медленно решаются вопросы согласования нормативно-законодательных актов регулирующих и стимулирующих научно-техническую деятельность; нет стратегии развития машиностроения; не исследованы проблемы эффективного взаимодействия научно-исследовательских организаций в институтах РАН.

По мнению экспертов, в машиностроительной отрасли вопросам исследования и изучения факторов формирования инновационно-технологического потенциала уделяется недостаточно времени. Практика привлечения к исследованию научно-исследовательских институтов минимизирована из-за отсутствия приемлемо- го финансирования в рамках НИОКР.

В целом в отечественном машиностроении за последние 20-25 лет непосредственно на такие исследования выделялось средств в 7-9 раз меньше, чем в 1983-1987 годах. При этом доля затрат на НИОКР и маркетинговые исследования растет очень медленно, что не позволяет своевременно создавать научно-технический задел (НТ3) и вести подготовку к выпуску новой продукции высокими темпами. Следует отметить отсутствие систематической практики изучения рынка новых прогрессивных технологий, которые в дальнейшем могли бы стать определяющими направлениями научно-технологического прогресса, опираясь на инновации.

Недостаточно времени уделяется изучению факторов, влияющих на прогрессивное изменение технологических ресурсов машиностроительных предприятий. Формы материального стимулирования персонала предприятий и организаций, ответственных за прикладную часть НИОКР, рудиментарна и требует полной переоценки. Это влияет на темпы совершенствования инновационной деятельности, как промышленных предприятий в частности, так и в целом машиностроительном комплексе. Особое место занимает проблема ценообразования научно-технической продукции в цепочке «Разработчик-Производитель-Потребитель».

Отсутствие системной работы исследования рынка новых технологий, по мнению экспертов, является следствием недостаточного уровня обеспечения информационного и кадрового, а также недостаточное использование зарубежного опыта.

В стадии решения находятся следующие организационно-экономические задачи:

- научно-техническое прогнозирование, отраслевое и межотраслевое;

- научно-методическое, кадровое, информационное и правовое обеспечение;

- стимулирование - материальное, финансирование, ценообразование.

Устранению, сложившихся негативных факторов, могло бы помочь создание в регионах межотраслевых научно-технических центров, инновационных центров типа «Сколково». Это помогает концентрировать кадровый, научно-исследовательский и инвестиционный потенциал и решить многие потребности машиностроительных предприятий разного профиля. Высокие темпы научно-технического развития 
машиностроительной отрасли достижимы при создании оптимальной концентрации государственных средств на перспективных направлениях развития наукоемких технологий. Как указывают эксперты, за последние десятилетия, технологическая структура инвестиций в основной капитал машиностроительного комплекса является экономически неоптимальной. В современных условиях регионы страны с большим объемом наукоемкой продукции должны: произвести оценку эффективности участия государственного сектора в направлении НИОКР; на научной основе разработать и реализовать организационно-экономические мероприятия по долгосрочному прогнозированию научно-технического прогресса; на уровне государства решить вопросы исполнения государственного заказа по реализации НИОКР; улучшить систему материального стимулирования реализации научно-технических программ совершенствования современных технологий; использовать более эффективно инновационно-технологический потенциал предприятий машиностроения стран содружества и дальнего зарубежья; обеспечить изучение в вузах курса «технологическая статистика»; реформировать базовый курс «технология машиностроения» в ведущих вузах России. Наиболее слабым звеном в системе развития научно-технологического потенциала машиностроения является совершенствование технологий в заготовительных производствах машиностроения, где в итоге создаются условия повышения качества продукции. В системе управления качеством развития материально-технической базы машиностроения особое значение имеет повышение качества базовых технологий. По предложению профессора Б.Я. Татарских возможно использовать такой критерий, как Темп кач.техн.- темп качества технологии, характеризующий технологическое развитие предприятия. В указанный критерий входят следующие производные:

Ткач.инф.рес. - темп качества информационных ресурсов;

Ткач.мат. - темп качества материалов (металла);

Ткач.обор. - темп качества оборудования;

Ткач.НИОКР - темп качества научно-исследовательских и опытно-конструкторских работ;

Ткач.p.c. - темп качества рабочей силы;

Ткач.э.н. - темп качества энергоносителей;

Ткач.т.п. - темп качества технологической подготовки;

При исследовании динамики развития технологического потенциала данные о качестве технологии можно использовать как инструмент совершенствования механизма стимулирования работников инженерно-технических служб, а также для прогнозирования результативности научно-исследовательской деятельности, связанной с повышением уровня технологического развития предприятий отрасли. Динамика темпа качества базовых технологий в машиностроении позволяет судить об экономическом и производственном потенциале предприятий и в определенной степени может служить фактором инвестиционной привлекательности конкретных предприятий. Рассматриваемая динамика достаточно объективно характеризует и состояние инновационной деятельности в современном машиностроении. Для исследования тенденций качества базовых технологий (в зависимости от отраслевой специфики) необходимы данные за ряд лет, часть которых может быть получена на основе экспертных оценок с привлечением ученых НИИ, КБ и вузов. Создание банка данных по основным параметрам динамики технологий является важным условием управления НТП на машиностроительных предприятиях.

В настоящее время в машиностроении страны наибольший объем финансирования для развития наукоемких технологий требуется на весь цикл научно-технической деятельности, которые следует направлять для реализации важных мероприятий, к которым относятся:

- формирование информационно-поисковых систем, включая сеть «Интернет» для создания базы данных о «двойных» технологиях в системе ОПК (отечественных и зарубежных предприятий);

- создание банка данных о научно-технологическом потенциале конкурентов в странах Запада, США и Японии;

- проведение целевых научных командировок и подготовка специалистов в базовых ВУЗах страны и в ведущих зарубежных университетах;

- организация научно-исследовательской работы в НИИ, ВУЗах, отраслевых научно-исследовательских организациях и научно-технических центрах ведущих предприятий машиностроения (например, в автостроении, самолетостроении, ракетостроении, приборостроении); 
- выполнение научно-технической экспертизы результативности уровня технологии для проведения мониторинга рейтинга критических технологий в машиностроении;

- организация целевой подготовки инженеров-исследователей по инновационному менеджменту и прогнозированию НТП для реализации программ стратегического характера на предприятиях ОПК с целью эффективного использования технологий двойного назначения.

В ведущих машиностроительных центрах России, имеющих высокую долю производства наукоемкой продукции, необходимо: определить значимость государственного сектора для выполнения НИОКР; обосновать организационно-экономические мероприятия по совершенствованию национальной системы долгосрочного прогнозирования научно-технологического прогресса; на государственном уровне решить проблемы перехода к адресной системе стимулирования выполнения особо важных заказов на работы по НИР; совершенствовать методы и механизмы экономического стимулирования реализации научно-технических программ внедрения прогрессивных технологий. В условиях конкуренции в наукоемких подотраслях отечественного машиностроения опережающий характер использования стандартизации является значительным фактором выхода товаропроизводителей на внешний рынок. Безусловно, главная роль здесь принадлежит кадровому обеспечению развития современных наукоемких технологий, освоение которых невозможно без специалистов высокого класса.

В современных условиях целевая подготовка специалистов в области инновационного менеджмента должна финансироваться по приоритетному принципу за счет средств Федерального бюджета для ведущих государственных вузов. Во многом это важнейшее условие повышения эффективности НИИ и ОКР в базовых отраслях, создающих сложную наукоемкую продукцию, в том числе и с целью обеспечения технологической безопасности и обороноспособности страны.

Отечественные ученые отмечают, что дальнейшее развитие технологической базы машиностроения предполагает, прежде всего, повышение роли государственного управления научно-технологическим прогрессом в базовых отраслях путем целевого полномасштабного финансирования НИИ системы РАН и отраслевых научно-исследовательских центров и ведущих вузов.

Требуется постоянное совершенствование информационного и кадрового обеспечения в сфере новых технологий; оптимизация структуры отделов конструкторов и технологов и совершенствование методов стимулирования их труда. С целью ускорения внедрения научно-технических достижений необходимо:

- совершенствование структуры инвестиций научно-технологического назначения в пользу НИОКР и разработок технологического маркетинга на этапе создания научно-технического задела (НТ3);

- ускорение темпов инвестирования НИОКР в том числе за счет средств целевых научно-технических программ общегосударственного значения;

- реализация резервов развития технологии двойного назначения в подотраслях, связанных с оборонно-промышленным комплексом (ОПК);

- совершенствование методов оценки эффективности внедрения наукоемких технологий в ведущих подотраслях машиностроения;

- постоянное совершенствование методов ценообразования при применении новых технологий в ОПК и гражданском машиностроении с учетом всего многообразия рыночных факторов;

- научный анализ динамики жизненного цикла новых технологий;

- разработка методов комплексной оценки социально-экономического эффекта от внедрения новых технологий;

- комплексное внедрение нанотехнологий с целью создания новых материалов с заранее заданными физико-химическими и физикотехническими свойствами;

Управление инновационно-технологическим потенциалом предполагает решение многих задач, которое возможно только при целевой поддержке базовых отраслей экономики со стороны государства, исходя из стратегии определенных приоритетов страны на ближайшие 15-20 лет. Концентрация основных ресурсов для внедрения новых технологий необходима как на федеральном, так и региональном уровнях, когда есть реальные экономические интересы формирования основных предпосылок конкурентных преимуществ товаропроизводителей в стране. 
Необходимо отметить, что эффективная концентрация ресурсов важна в тех случаях, когда ресурсов федерального и регионального инвестирования развития научно-технологического потенциала предприятий машиностроения недостаточно для реализации инновационных программ формирования технополисов, технопарков, инновационных центров.

Для ускорения развития материально-технической базы машиностроения требуется совершенствование базовых механизмов стимулирования, что предполагает льготное налогообложение, когда прибыль направляется на реализацию проектов (программ) преимущественно на инновационной основе; используется льготное налогообложение на прибыль, направляемую для развития новых технологии и технологии двойного назначения, существенная эффективность которых может быть достигнута на предприятиях отечественного машиностроения.

Повышение научно-технологического потенциала машиностроительного комплекса является важнейшим фактором эффективного развития всей отечественной промышленности.

\section{Библиографический список}

1. Баженов В.А., Соколов А.В. Высокотехнологическое и наукоемкое производство: проблемы и неопределенность будущего //ЭКО.2014, № 1. с. 18-23.

2. Горохова А.Е. Повышение эффективности промышленных предприятий в условиях трансформирующейся экономики: монография. Москва. 2015. С. 43-48; 110-115.

3. Татарских Б.Я. Экономические и организационно-технологические проблемы развития машиностроения России: монография. Самара. 2017. 252 с.

4. Федоров О.В., Татарских Б.Я., Якушева А.М. Приоритетные отрасли новых технологических укладов. Монография. Москва. 2016. С. 39-43.

5. Радукин В.П. Производительность труда в машиностроении и резервы ее роста. Москва. 1987. 158 с. 